\title{
Flora das cangas da Serra dos Carajás, Pará, Brasil: Sapotaceae
}

\author{
Flora of the canga of Serra dos Carajás, Pará, Brazil: Sapotaceae
}

Mário Henrique Terra-Araujo ${ }^{1,2}$ \& Daniela Cristina Zappi,

\begin{abstract}
Resumo
Uma única espécie de Sapotaceae, Chrysophylloideae, Pouteria ramiflora, ocorre sobre canga na Serra dos Carajás, estado do Pará, Brasil. Este trabalho apresentada uma descrição detalhada, fotografias e comentários morfológicos sobre esta espécie.
\end{abstract}

Palavras-chave: afloramentos ferrosos, canga, FLONA Carajás, florística, Pouteria.

\begin{abstract}
A single species of Sapotaceae, Chrysophylloideae, Pouteria ramiflora, occurs on iron-stone (canga) at the Serra dos Carajás, Pará, Brazil. This paper presents a detailed description, photographs and comments regarding this species.
\end{abstract}

Key words: iron-ore outcrops, canga, FLONA Carajás, floristics, Pouteria.

\section{Sapotaceae}

Árvores, arvoretas, raramente arbustos, com látex geralmente de coloração branca no caule, ramos, folhas e frutos. Indumento malpighiáceo, em formato de «Y» sobre as diferentes estruturas da planta. Folhas simples, inteiras, alternas ou espiraladas, raramente opostas ou verticiladas. Estípulas presentes ou ausentes. Inflorescência fasciculada, usualmente solitária, axilar ou ramiflora, raramente cauliflora. Flores bi- ou unissexuais (planta monoica ou dioica); cálice com 4-6 sépalas em um ou dois verticilos; corola tubular, menos frequente rodada, gamopétala, 4-6(-9) lóbulos inteiros ou divididos; estames isostêmones, opositipétalos, 5-6; estaminódios 0-6 alternados com os estames; ovário súpero 1-5(-15)-loculado, estilete curto, simples, estigma reduzido. Frutos bacáceos geralmente suculentos, pericarpo e epicarpo carnosos, 1 a 5 -seminados; sementes com testa brilhante com cicatriz do hilo visível.

Família pantropical com aproximadamente 1.250 espécies distribuídas em 58 gêneros (Swenson \& Anderberg 2005; Swenson et al. 2008), dos quais 12 ocorrem no Brasil, representados por cerca de 230 espécies das quais a maioria (174) ocorre na Amazônia (BFG
2015). Possui representantes cultivados devido aos frutos comestíveis, como os diferentes tipos de sapoti (diversas espécies de Pouteria Aubl. e também Manilkara zapota (L.) P. Royen), sendo que o látex desta última espécie é utilizado na fabricação de uma substância vegetal conhecida como chicle, utilizada na manufatura de goma de mascar. Coletores de "balata" extraem borracha de espécies de maparajuba (Manilkara spp.) na calha norte da Amazônia. Também de importância econômica são as espécies asiáticas de Palaquium Blanco, cujo látex é conhecido como guttapercha, um tipo de borracha de amplo uso, incluindo desde próteses dentárias até mangas de isolamento para cabos e outros usos industriais (Burkil 1936).

\section{Pouteria Aubl.}

Árvores ou arvoretas, raramente arbustos. Folhas alternas e espiraladas, às vezes agrupadas na porção distal dos ramos. Estípulas ausentes. Inflorescências laterais, axilares ou ramifloras. Cálice em um único verticilo, 4-6 lobado, lobos imbricados, inteiros; corola curtamente tubulosa, 4-6(-9) lobos simples, alva, creme ou esverdeada; estames 4-6(-9), estaminódios usualmente em igual número ao dos lóbulos da

\footnotetext{
${ }^{1}$ Instituto Nacional de Pesquisas da Amazônia, Prog. Pós-Graduação em Botânica, Av. André Araújo 2936, 69067-375, Manaus, AM, Brasil.

${ }^{2}$ Faculdade Estácio do Amazonas, Av. Constantino Nery 3693, 69050-001, Manaus, AM, Brasil.

${ }^{3}$ Instituto Tecnológico Vale de Desenvolvimento Sustentável, R. Boaventura da Silva 955, 66055-090, Belém, PA, Brasil.

${ }^{4}$ Autor para correspondência: danielazappi14@gmail.com
} 
corola; ovário globoso a ovoide, 1-6(-15) locular, estilete curto (muito menor que o comprimento do ovário), estigma reduzido, lóculos uni a multi-ovulados. Fruto baga, 1-paucisseminada, sementes castanhas, brilhantes, arredondadas ou aplanadas. Gênero compreendendo cerca de 200 espécies de árvores neotropicais (Pennington 1990, Killeen et al. 1993, Swenson et al. 2013), conta com 122 espécies no Brasil das quais 46 ocorrem no Pará (BFG 2015).

1.1. Pouteria ramiflora (Mart.) Radlk., Sitzungsber. Math.-Phys. Cl. Königl. Bayer. Akad. Wiss. München 12: 333. 1882. Fig. 1a-b

Arbustos a árvores, 1,5-8 m alt., tronco muitas vezes ramificado na base, ritidoma espesso nas partes mais velhas, látex branco, ramos jovens ferrugíneos distalmente, glabrescentes na porção proximal. Folhas pecioladas, pecíolo $5-10 \mathrm{~mm}$ compr., lâmina $(3,5-) 4-9(-10) \times(2-) 2,5-4(-5)$ $\mathrm{cm}$, largamente elíptica, ovada ou lanceolada, base aguda a atenuada, ápice agudo a acuminado, cartácea, verde olivácea, lustrosa e mais escura adaxialmente, mais clara e opaca abaxialmente, nervuras 8-11 pares, glabras ou com tricomas ferrugíneos esparsos, principalmente próximos da base da nervura central. Inflorescências 1-3 -floras; flores 4-5-meras, não ultrapassando o comprimento dos pecíolos, brácteas e bractéolas triangulares, inconspícuas; pedicelos ferrugíneos, delgados, espessados distalmente; botões florais globosos; lobos do cálice 1,6-1,8 mm compr., arredondados a ovais, côncavos, externamente com tricomas ferrugíneos; corola verdeclara, 1,4-1,5 mm compr., lobos fimbriados, ultrapassando o comprimento do cálice, eretopatentes na antese. Bagas globoides, com ápice estipitado, 1,2-1,8(-2) cm diâm., inicialmente verdes e densamente cobertas de tricomas ferrugíneos, passando a castanhas e glabrescentes a totalmente glabras; sementes 1(-2), ovoides, 1-1,2 cm compr., castanho-claras, hilo branco.

Material selecionado: Canaã dos Carajás, S11A, 6²0'06"S, 50²6'19'”, 700 m 3.VIII.2010, fl., L.V. Silva 993 (BHCB); S11D, 6²4'29”S, 50¹9'39"W, 650 m, 2.X.2009, fl., P.L. Viana 4312 (BHCB); Serra do Tarzan, 6 ${ }^{\circ} 19^{\prime} 45^{\prime}$ "S, $50^{\circ} 08^{\prime} 26^{\prime}$ "W, 756 m, 1.IX.2015, fr.,
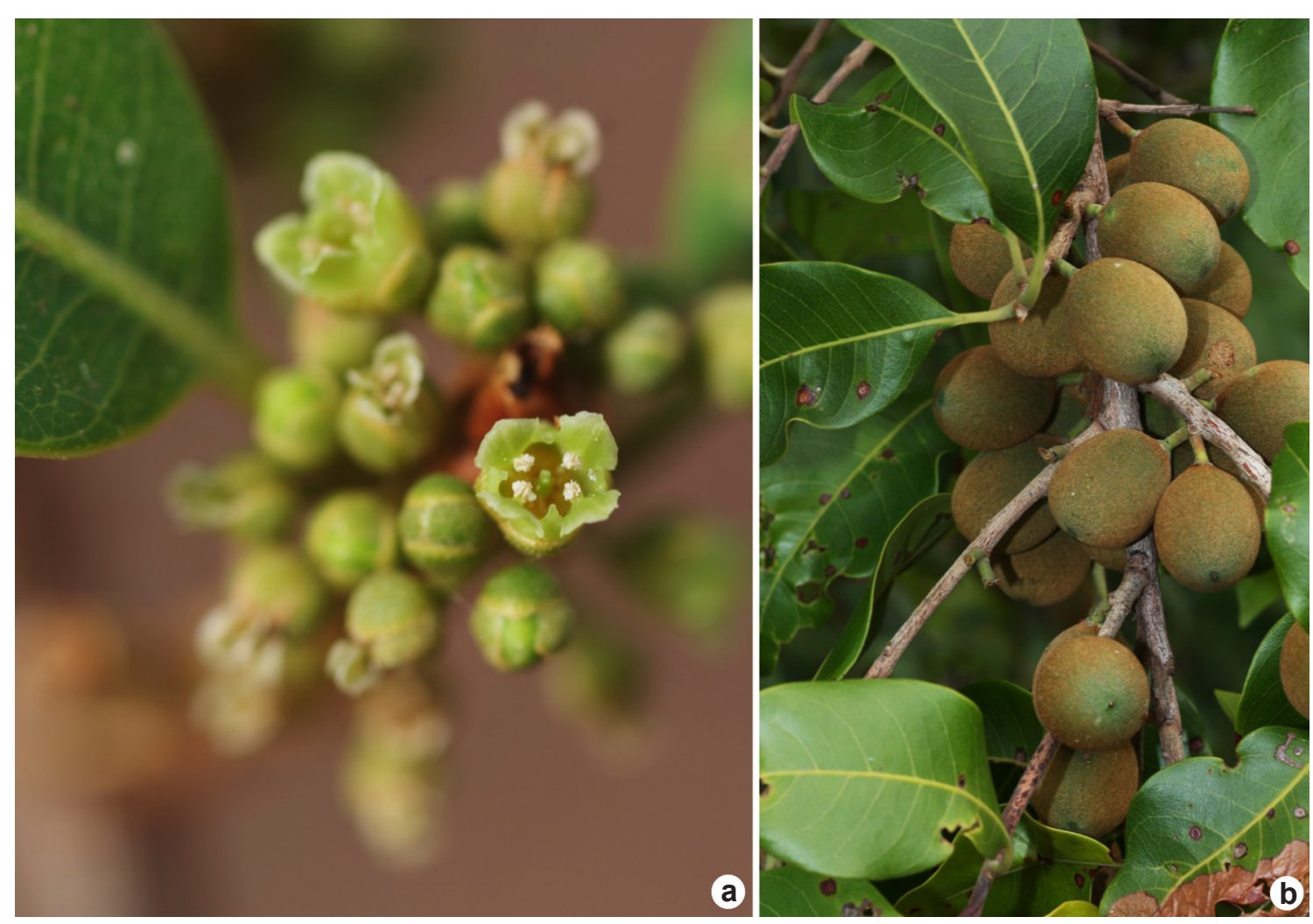

Figura 1 - a-b. Pouteria ramiflora - a. flores em botão e abertas; b. ramo com frutos. Fotos: a. N.F.O. Mota, b. A.O. Simões. Figure 1-a-b. Pouteria ramiflora - a. flower-buds and open flowers; b. fruiting branch. Photos: a. N.F.O. Mota, b. A.O. Simões. 
R.M. Harley 57334 (MG). Parauapebas, N1, 601'34" S, 5007'43" W, 663 m, 31.VIII.2015, fr., P.L. Viana 5784 (MG); N2, 6003'16" S, 50¹5'14"' W, $680 \mathrm{~m}$, 23.VI.2015, N.F.O. Mota 3388 (MG); N3, 603'16'”, $50^{\circ} 15^{\prime} 14$ "'W, $678 \mathrm{~m}, 14$.VI.2015, fl., N.F.O. Mota 3378 (MG); N4, 6²9'22"'S, 50¹0'16"'W, 25.VI.2015, fl., J.R. Trindade 251 (MG); N6, 607'51'"S, 50¹0'33W, fl., 3.IX.2014, fl., A. Gil 522 (MG).

Embora Pouteria ramiflora apresente uma considerável variação na forma de suas folhas, indumento e venação ao longo de sua distribuição geográfica tanto na região de Carajás como no âmbito mais amplo, a espécie pode ser reconhecida pelas folhas elípticas a lanceoladas, pubescentes, com nervuras intersecundárias bem desenvolvidas, estendendo-se até a margem, fascículos axilares com corola reduzida e frutos pequenos, 1-2-seminados, densamente pilosos a glabrescentes.

Pouteria ramiflora ocorre na Bolívia, Brasil e Paraguai, preferencialmente em ambientes abertos. No Brasil tem uma distribuição com tendência centro-oriental (apesar de ocorrer em Rondônia), com registros também no Sudeste (Minas Gerais, Rio de Janeiro e São Paulo), Nordeste (Bahia, Ceará, Maranhão, Pernambuco e Piauí), todos estados do Centro-Oeste e Distrito Federal, além da região Norte (Pará, Rondônia e Tocantins) (BFG 2015). Na Serra dos Carajás ocorre em capões e na beira de lajedos de canga da Serra Norte: N1, N2, N3, N4 e N6, na Serra Sul: S11A e S11D e Serra do Tarzan.

\section{Agradecimentos}

Os autores agradecem ao Instituto Tecnológico Vale (01205.000250/2014-10) e CNPq (455505/2014-4) pelo financiamento e a Nara F.O. Mota e André O. Simões pelas fotografias cedidas.

\section{Referências}

BFG - The Brazil Flora Group (2015). Growing knowledge: an overview of seed plant diversity in Brazil. Rodriguésia 66: $1085-1113$.

Burkill IH \& Birtwistle W (2002) A dictionary of the economic products of the Malay Peninsula. Vol. 2. Ministry of Agriculture of Malaysia, Kuala Lumpur. Pp. 1651-1672

Killeen TJ, García E \& Beck SG (1993) Guía de Arboles de Bolivia. Herbario Nacional de Bolivia, La Paz, Missouri Botanical Garden. 958p.

Swenson U \& Anderberg AA (2005) Phylogeny, character evolution, and classification of Sapotaceae (Ericales). Cladistics 21: 101-130.

Swenson U, Richardson JE \& Bartish IV (2008) Multigene phylogeny of the pantropical subfamily Chrysophylloideae (Sapotaceae): evidence of generic polyphyly and extensive morphological homo- plasy. Cladistics 24: 1006-1031.

Swenson U, Nylinder S \& Munzinger J (2013) Towards a natural classification of Sapotaceae subfamily Chrysophylloideae in Oceania and Southeast Asia based on nuclear sequence data. Taxon 62: 746-770.

Pennington TD (1990) Flora Neotropica Monograph 52: Sapotaceae. New York Botanical Garden, New York. 770p.

\section{Lista de exsicatas}

Almeida TE 2490 (1.1). Costa LV 993 (1.1). Daly DC 1735 (1.1). Gil A 522 (1.1). Harley RM 57334. Lobato LCB 3755 (1.1), 4295 (1.1), 4439 (1.1). Mota NFO 1086 (1.1), 3378 (1.1), 3388 (1.1). Reis AS 38 (1.1). Ribeiro RD 1336 (1.1). Rosa NA 4666 (1.1). Sales J 10 (1.1). Santos RS 24 (1.1), 151 (1.1). Silva LV 993 (1.1). Sperling CR 5632. Trindade JR 251 (1.1). Vasconcelos LV 919 (1.1), 956 (1.1), 957 (1.1), 1044 (1.1), 1045 (1.1). Viana PL 4315 (1.1), 5784 (1.1), 5785 (1.1). Zappi DC 3565 (1.1). 
